
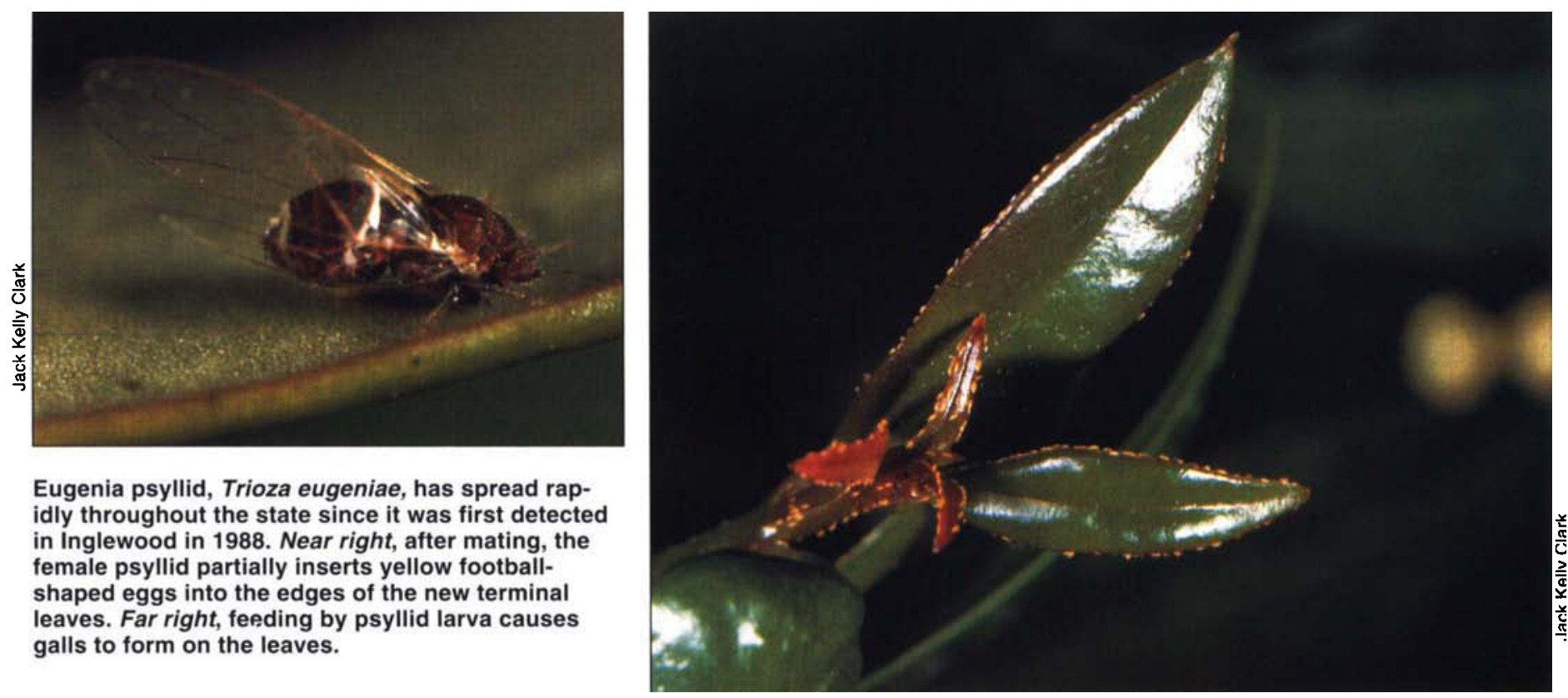

Eugenia psyllid, Trioza eugeniae, has spread rapidly throughout the state since it was first detected in Inglewood in 1988. Near right, after mating, the female psyllid partially inserts yellow footballshaped eggs into the edges of the new terminal leaves. Far right, feeding by psyllid larva causes galls to form on the leaves.

\title{
Parasitoid shows potential for biocontrol of eugenia psyllid
}

\author{
Donald L. Dahlsten a Donald M. Kent a David L. Rowney \\ William A. Copper $\square$ Terri E. Young $\square$ Richard L. Tassan
}

The eugenia psyllid has become a major pest of eugenia, a commonly used ornamental plant in the coastal counties of California. Attempts to control this insect with insecticides have been only partially successful. A biological control program was initiated at Disneyland in Southern California in 1991. A monitoring procedure has been developed and a eulophid parasitoid, Tamarixia $n$. sp., was introduced from Australia in July 1992. Initial results indicate that the parasitoid has become established and has spread widely in a short period of time. Sampling shows a correlation between numbers of psyllids and parasitoids and a post-release decrease in the number of psyllids.
In California the eugenia psyllid, Trioza eugeniae Froggat, is a relatively recent pest of eugenia, Syzygium paniculatum (Australian brush cherry as it is known in California, or lilly pilly as it is referred to in Australia). First detected in May 1988 by a homeowner in Inglewood, Los Angeles County, the psyllid had spread to Orange and San Luis Obispo counties by September, and to Santa Barbara, Ventura and San Diego counties by the end of 1988. The psyllid spread to Northern California early in 1989, with reports of its occurrence in San Mateo, Santa Clara, Alameda, San Francisco, Contra Costa and Santa Cruz counties. Subsequent occurrences have been reported from as far north as Marin and Napa counties, but not from any Central Valley counties. The rapid spread of the eugenia psyllid may have been facilitated by the movement of nursery stock throughout the state.

Observations on the biology of the psyllid were initiated at the Laboratory of Biological Control, UC Berkeley in Albany, and at other locations in Alameda County in 1989-90. Some endemic natural enemies have been noted to prey on the psyllid in California, but their effects on psyllid abundance have been negligible.

The eugenia psyllid is multivoltine, with three to five or more overlapping generations annually, apparently determined by the interaction of temperature and the physiological state of the host plant. After mating, the female psyllid partially inserts yellow football-shaped eggs into the edges of the new terminal leaves. Small mobile nymphs hatch from the eggs and settle on the new expanding leaves, prima- 


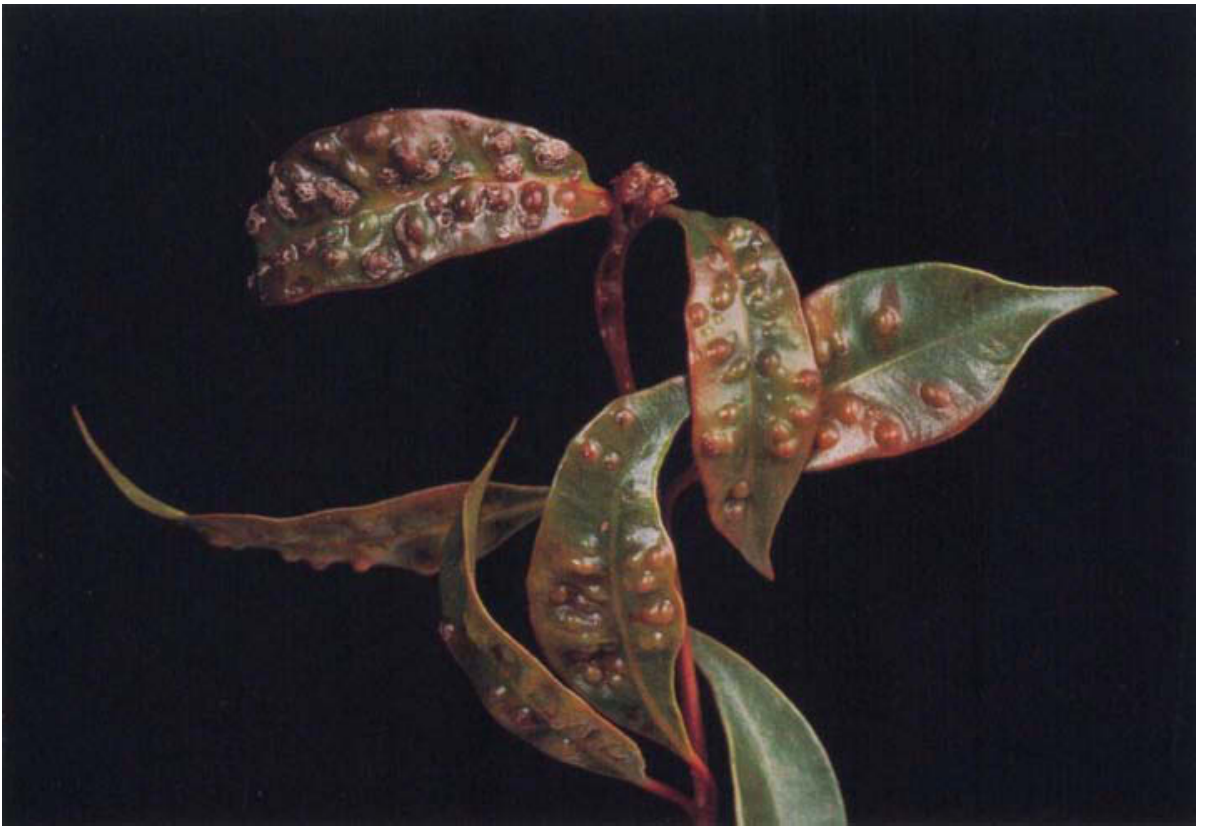

rily on the underside, where they feed and develop in cup-shaped pits or galls formed by the plant's response to the psyllid's feeding.

Acute damage caused by high psyllid densities includes inhibition of new shoot formation, distortion of new foliage and stems, and a spoiled plant appearance caused by black sooty mold growing on the honeydew produced by the psyllids. Chronic effects of sustained infestation are well documented, and include severe weakening of plants, poor growth characteristics and lowered economic value.

Eugenia, a small tree, has been used as an ornamental for many years in eastern and southern Australia. In California it is commonly used as an ornamental tree, shrub, hedge or topiary. At Disneyland in Anaheim, Orange County, it is an extremely important plant. Over 800 meters of hedges are used as visual screens in and around Disneyland. Moreover, some of the key topiary characters are fashioned from eugenia. Psyllid damage to the hedges at Disneyland was widespread in 1991. Acephate and fluvalinate were applied to the hedges at regular intervals in an effort to limit the damage, but it was clear that an alternative, long-term solution, one less reliant on pesticides, was needed to preserve the aesthetic quality of the plants.

\section{Foreign exploration}

The eugenia psyllid is presumed to be a native of Australia as its primary host plant, S. paniculatum, is native to sandy soils and stabilized sand dunes in the coastal areas of New South Wales. However, little has been published on the biology of the eugenia psyllid or its natural enemies. Damage caused by the psyllid can be found in Australia, but it has not been extensive enough to concern homeowners.

Therefore it has been inferred that natural enemies may be controlling the psyllid in Australia.

A search for natural enemies of the psyllid was initiated in late 1991 at several locations within the host plant range. Parasitized psyllids were collected from native stands of $S$. paniculatum in New South Wales and from ornamental plants in Victoria and South Australia; these were sent to UC quarantine facilities in Albany. Three shipments were made between November 1991 and January 1992. The primary parasitoid obtained from these shipments was a eulophid wasp, a new species in the genus Tamarixia, which made up $84 \%$ of the parasitized psyllids. Four species of hyperparasitoids were also reared from these shipments, but were destroyed in quarantine. In June 1992, permission was received from the U.S. De- partment of Agriculture and the California Department of Food and Agriculture to remove Tamarixia from quarantine.

Tamarixia is a small external parasitoid of the eugenia psyllid. The female is readily distinguished from the male by the large dorsal yellowish spot on the anterior of the abdomen. The parasitoid inserts an egg between the leaf tissue and the underside of the psyllid nymph in the small gall created by the psyllid feeding. Psyllid nymph instars two through five are susceptible to oarasitism, but instars three and four 훌 seem to be preferred. A small larva hatches from the egg and eventually kills the psyllid. The larva transforms into a new adult under the psyllid carcass. The new adult chews a hole in the dorsum of the carcass, emerges and starts the next generation of Tamarixia. A Tamarixia generation takes about 14 days in our laboratory, at a temperature of $68^{\circ}$ to $75^{\circ} \mathrm{F}\left(20^{\circ}\right.$ to $24^{\circ} \mathrm{C}$ ). Our field observations suggest that outdoors, the period from egg to adult takes 3 to 6 weeks during the warm summer months; in the winter it may take several months.

\section{Sampling method}

One of the first steps in our program was to develop a sampling method. Fluorescent yellow sticky traps have been used successfully for years for small adult homopterans, so we decided to try sticky traps to monitor adult eugenia psyllids.

A trap consists of two plastic lids, 4.1 inches $(10.5 \mathrm{~cm})$ diameter. A clear lid coated with STP motor oil additive on the upper surface is placed over a second lid that has been painted fluorescent yellow and has had its lip removed. The yellow lid is held in place by a Velcro strap and can be attached to a large wire, a fence or a rod near the bush to be sampled. The upper sticky lid is held in place with a clip. The coated lids were exchanged weekly and the insects counted under a microscope.

In 1991, preliminary studies at our laboratory in Albany indicated that 
fluorescent yellow sticky traps attracted adult eugenia psyllids. Another series of color attraction tests was conducted in Alameda County to determine whether fluorescent yellow is the most effective trap color for Tamarixia as well as for the psyllid. Fluorescent-blue, pink, red and green were compared with enamel-blue, pink, orange, lavender, white and black.

Fluorescent yellow was tested over a period of several months against the other colors three at a time in a 4-by-4 Latin Square design. Each color scheme was replicated over 2 consecutive weeks. The array was placed approximately 12 inches $(30 \mathrm{~cm})$ from a eugenia bush, with the sticky surfaces facing outward. Statistical tests were restricted to colors tested simultaneously. Data analyses (analysis of variance and Tukey's HSD test, $P<$ 0.05 ) showed that fluorescent yellow trapped significantly more eugenia psyllids and Tamarixia than any other color except fluorescent green (fig. 1). This suggests that both the psyllid and its parasitoid are attracted to these two colors, which are within the wavelength spectrum of 500 to 550 nanometers.
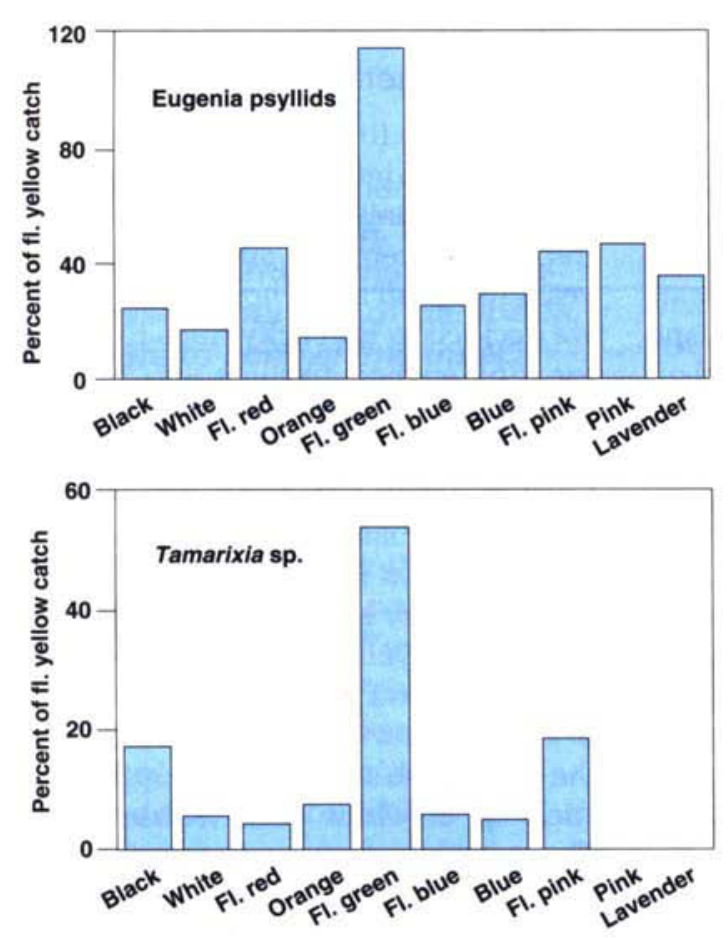

Fig. 1. Color preference of eugenia psylid and Tamarixia adults: percent of fluorescent yellow catch for other tested colors.

\section{Bio-control program monitoring}

To monitor psyllid and Tamarixia abundance, 10 sticky traps were attached to each of two Disneyland hedges on May 12, 1992: one hedge at Winston Gate, where there were no pest-control activities during the course of the study, and a second hedge bordering West Street, which was sprayed in 1992 and once in April 1993. The traps were placed at 5- to 10meter intervals, 2 to 3 meters high on the hedges. Six sticky traps were attached to a third hedge (Main Parking Lot) on February 16, 1993. The traps were changed weekly and the average number of adult psyllids and Tamarixia per trap was determined for each hedge and each week.

Beginning on February 12, 1993, we sampled the foliage of each hedge every 3 to 4 weeks. Foliage samples were sent to Albany for determination of the number of psyllids and parasitoids per tip. For the first four sample dates, we counted insects on each pair of leaves making up the first three nodes of each tip; subsequently we counted insects on one leaf from each of the first six nodes. Five tips were collected in the vicinity of each of the 26 sticky traps.

Data collected through late November 1994 indicate that timing of psyllid peak numbers varied, but the number of adult psyllids in traps usually peaked from April/May to June/July, and was generally lowest in fall and winter. A smaller peak sometimes occurred in mid- to late summer. Peak number of adult psyllids in 1992 ranged from 1,134 per trap at Winston Gate, to 97 per trap at West Street (fig. 2), to 15 per trap at the Main Parking Lot (not shown because of low numbers). A second, smaller peak (102 per trap) in adult psyllid numbers was evident at Winston Gate in late July/ August 1992, but this peak was very low in 1993 and not present in 1994. Similarly, a second peak was observed at the West Street site in July/August 1992, but not in 1993 or 1994. In contrast to the Winston Gate site, however, the number of adult psyllids at West Street in July/August 1992 was comparable (107 per trap) to that of April/May 1992. Adult psyllid numbers were low at the Winston Gate and West Street sites from September

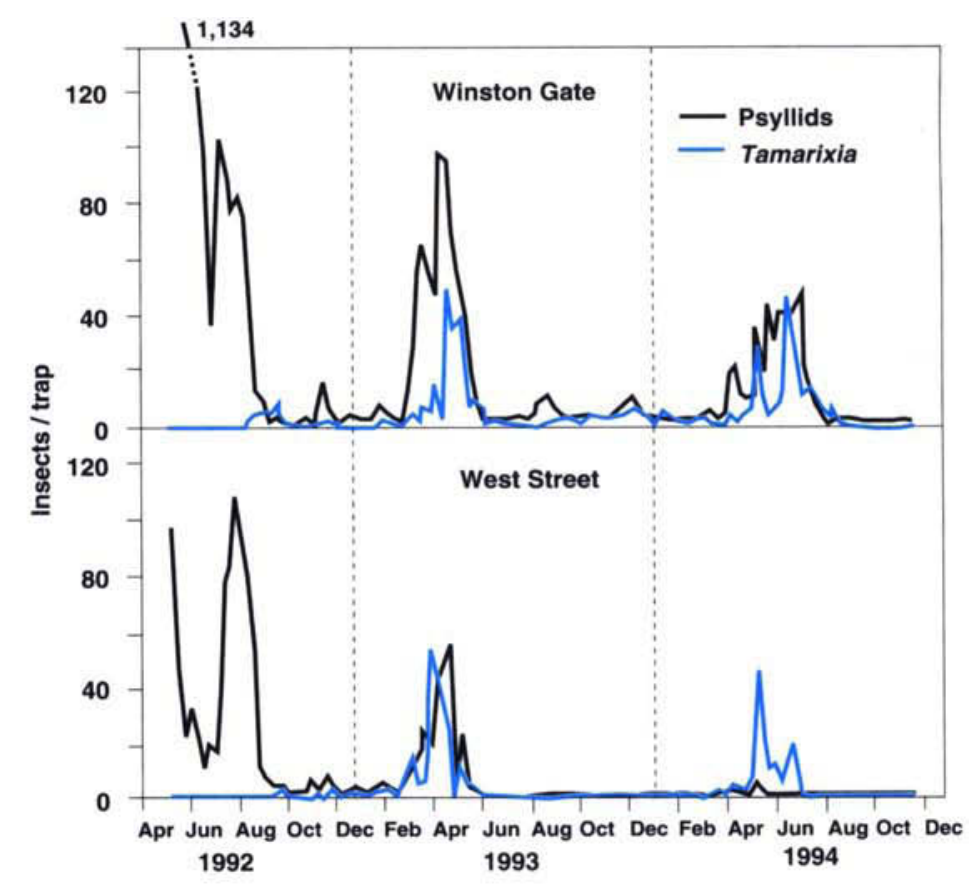

Fig. 2. Mean number of psyllids and Tamarixia per sticky trap at Winston Gate and West Street hedges, Disneyland, Anaheim, 1992-1994. 
through February, and at the Main Parking Lot site at all times of the year. In all of 1994 very few psyllids were captured, even during the peak periods, at the West Street and Main Parking Lot sites.

On July 8, 1992, 103 Tamarixia adults ( 78 females, 25 males) were released at the Winston Gate site. Tamarixia was first detected in traps at the Winston Gate site on August 4, 1992, four weeks after release, and at the West Street site 250 meters away on August 25, 1992. At the Winston site, the number of parasitoids increased in 1992, then diminished during the winter months. Tamarixia were captured in February 1993 when sampling was initiated at the Main Parking Lot, 300 meters from the release site. At all sites, peak numbers of Tamarixia caught in both 1993 and 1994 were similar to or greater than the number of psyllids caught (fig. 2).

The density of psyllid eggs per tip from the tri-weekly foliage samples correlates well $(r=0.834)$ with the adult psyllids caught in the sticky traps in the week preceding the foliage count (fig. 3). The density of psyllid large nymphs on the foliage samples follows a similar pattern to psyllid adults caught in traps, with peak numbers decreasing from 1993 to 1994 , while the proportion of nymphs parasitized increased steadily from 1993 to 1994 for both Winston Gate and West Streets (fig. 4). Almost no large nymphs were found at the main gate hedge in either year.

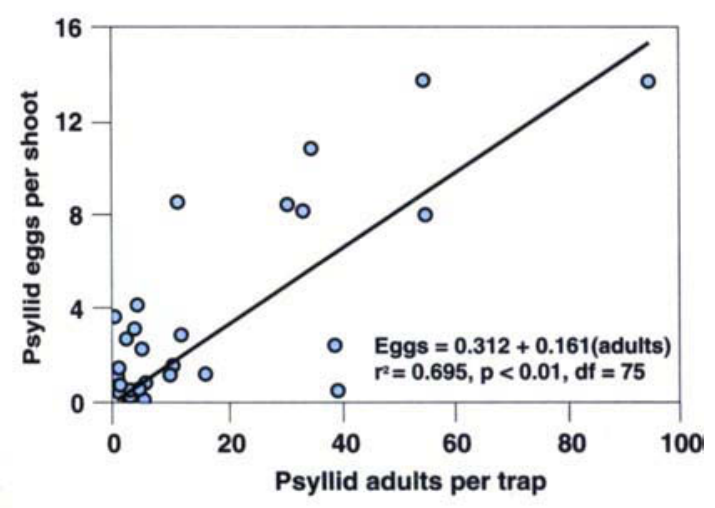

Fig. 3. Eugenia psyllid eggs per shoot versus psyllid adults per sticky trap (week of foliage sample) at Disneyland, Anaheim, 1993-1994.
For two reasons, our results suggest that Tamarixia is having an effect on the number of psyllids. First, we have identified a correlation between adult psyllids, psyllid density on foliage, and Tamarixia populations. At all three sites, the number of psyllids was low throughout the winter, began to increase in March/April, and peaked from April to July. Tamarixia exhibited a similar pattern.

A second indicator of Tamarixia effectiveness is that peak psyllid numbers decreased each year from 1992 to 1994 at both Winston Gate and West Street. At the Winston Gate site, the number of psyllids per trap peaked at 97 in 1993, more than a 10-fold decrease from the year before, and peaked at 48 in 1994, a $50 \%$ reduction from 1993 (fig. 2). The peak number of psyllids per trap at the West Street site was 56 in 1993, almost half that of the previous year, while in 1994 the peak dropped to less than 5, a 10-fold decrease from 1993. Both sites had lower late-summer peaks in 1993 compared to 1992 , and both had no late summer peak in 1994.

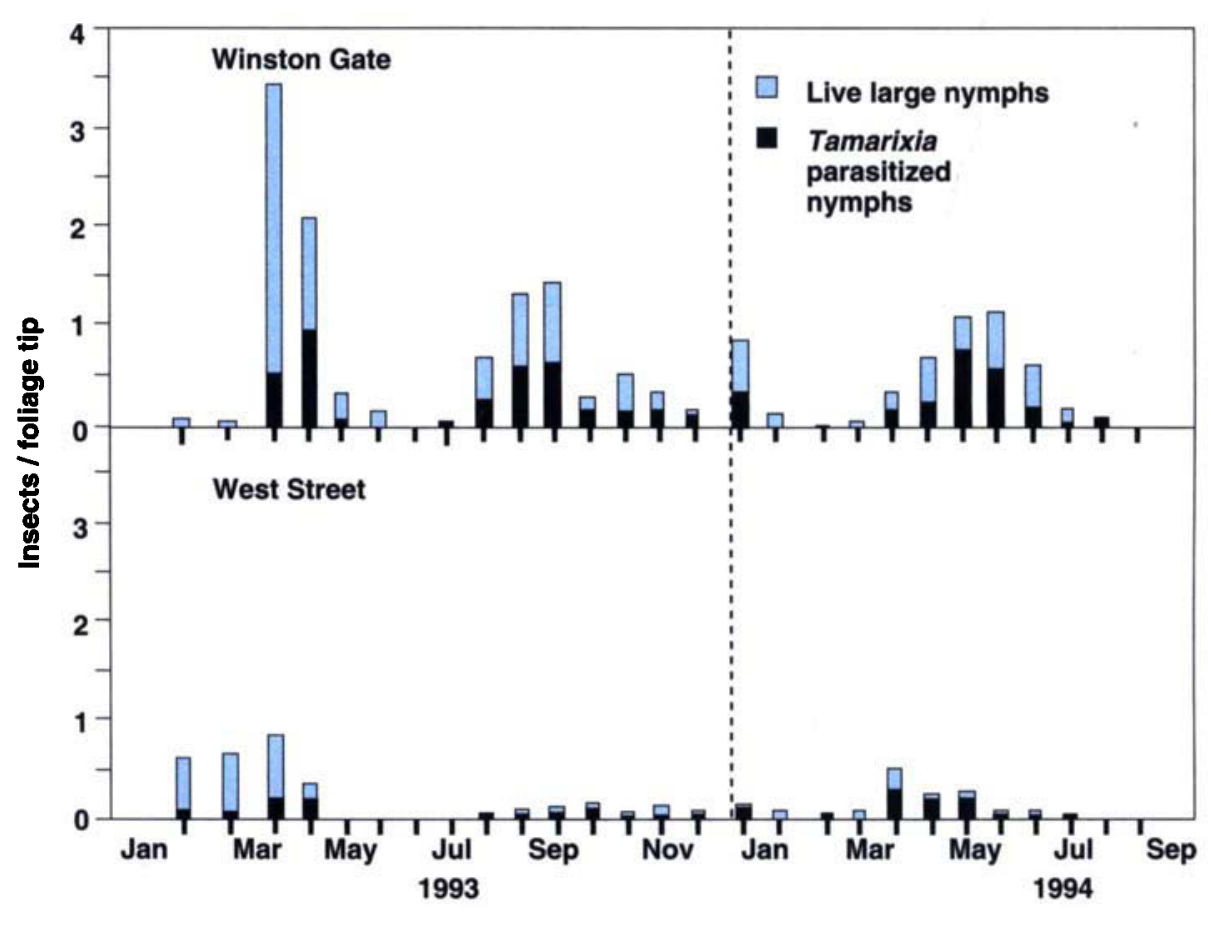

Fig. 4. Eugenia psyllid large nymphs, live and parasitized, in foliage samples at Winston Gate and West Street hedges in 1993-1994, Disneyland, Anaheim.

\section{Conclusions} are encouraging. Tamarixia survived its first two California winters, and appears to be established throughout the coastal areas of California. Tamarixia has been recovered in the cities of Irvine, Riverside, Glendale, Pasadena, Los Angeles, Santa Monica and Pacific Palisades, more than 40 miles from Disneyland. With this capacity for dispersal, further releases may not be necessary.

At our Disneyland study sites, fluctuations of the Tamarixia population are congruent with psyllid fluctuations, and the number of adult psyllids has decreased each year subsequent to release. No pesticide has been applied to any hedges since April 1993.

Further study is required to determine if Tamarixia can maintain psyllid populations at a level low enough to sustain existing hedges. An aesthetic injury level survey procedure has been established for use by the park landscape staff to ensure that control is adequate. The effects of pruning on psyllids must be determined, as the timing
The results of our program to date 
of pruning may either exacerbate infestations or help to control populations. Finally, if Tamarixia is unable to suppress psyllid populations adequately in future years, the effects of insecticide spraying on psyllids and Tamarixia must be determined. Each of these factors - Tamarixia, pruning and insecticide spraying - must be integrated into a management scheme that fits in with park operations and maintenance.

D.L. Dahlsten is Professor, D.L. Rowney is Biostatistician, W.A. Copper and R.L. Tassan are Staff Research Associates, and T.E. Young is Lab Assistant, Laboratory of Biological Control, UC Berkeley; and D.M. Kent is Ecologist, Walt Disney Imagineering, Research and Development, Glendale, California.

The authors appreciate the assistance of Robert F. Luck and Melissa Marcotte, UC Riverside; Ben Schwegler, Walt Disney Imagineering, Glendale; Fred Petit, Disney EPCOT Center, Florida; John Kabashima, Orange County Farm Advisor; Jason Herrera and Maria Lopez, Laboratory Assistants, and L. E. Caltagirone and K. S. Hagen, Professors emeriti, Laboratory of Biological Control, UC Berkeley; Ross P. Field and Raelene Kwong, Keith Turnbull Research Institute, Victoria, Department of Conservation, Forests and Lands, Frankston, Victoria, Australia; Graham Young, Ryde School of Horticulture, Ryde, New South Wales, Australia; and F. David Morgan (retired), Waite Agricultural Research Institute, University of Adelaide, Glen Osmond, South AustraIia, Australia. In addition, the authors wish to acknowledge the cooperation of Norm Doerges and Karen Hedges, Disneyland, Anaheim. This project was funded in part by Walt Disney Imagineering Research and Development, Glendale.

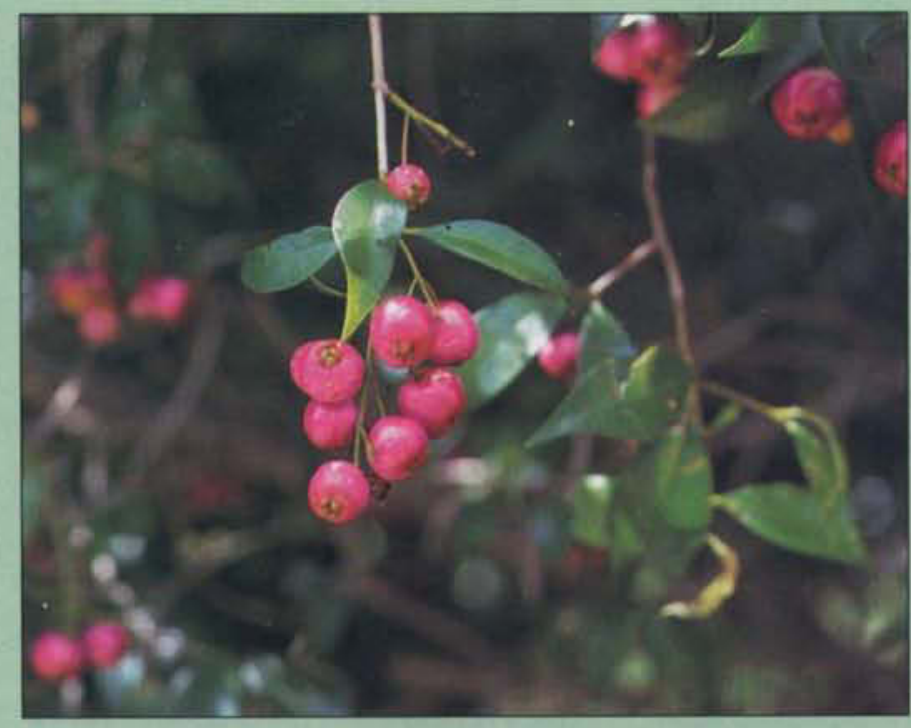

4 Eugenia, Syzygium paniculatum, is used extensively at Disneyland for hedges and topiary characters.
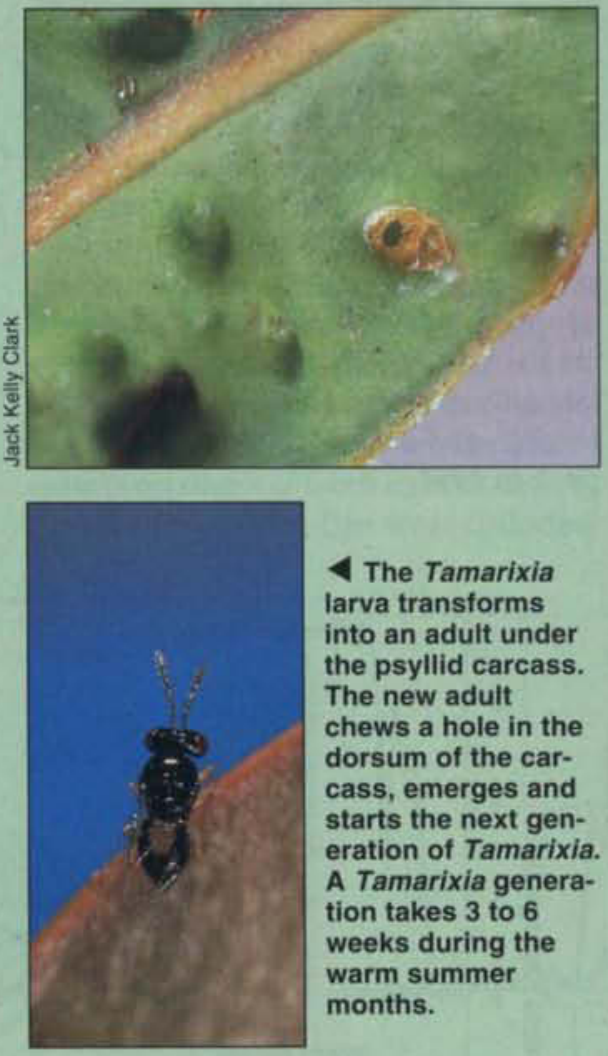

The Tamarixia larva transforms into an adult under the psyllid carcass. The new adult chews a hole in the dorsum of the carcass, emerges and starts the next generation of Tamarixia. A Tamarixia generation takes 3 to 6 weeks during the months. warm summer
The female Tamarixia sp. inserts her egg between the leaf tissue and the psyllid nymph. After the parasitoid larvae hatches from the egg, it eventually kills the psyllid.

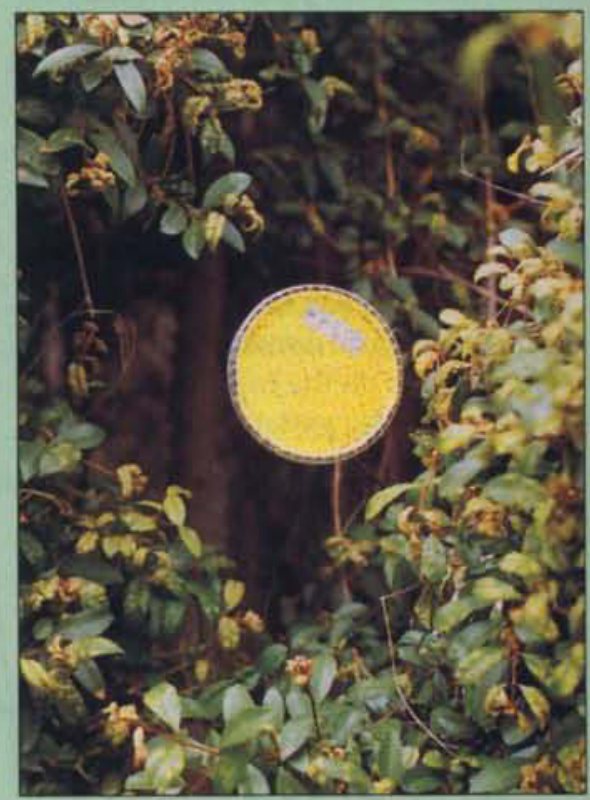

A Sticky traps were used to monitor

eugenia psyllid and Tamarixia adults.

\section{CALIFORNIA AGRICULTURE ASSOCIATE EDITORS}

Animal, Avian, Aquaculture and Veterinary Sciences

(assoc. editors to be announced)

Economics and Public Policy

Harold O. Carter

Alvin Sokolow

\section{Food and Nutrition}

Barbara Schneeman

Eunice Williamson

Human and Community Development

Linda M. Manton

Karen P. Varcoe
Land, Air \& Water Sciences

J. Brian Mudd

Garrison Sposito

Henry J. Vaux, Jr.

Natural Resources

Daniel W. Anderson

John Heims

Richard B. Standiford

Pest Management

Michael Rust

Frank Zalom

Plant Sciences

Calvin O. Qualset

G. Steven Sibbett 